\title{
Community paediatrics and public health: taking stock for the next millennium
}

The Calman reforms have forced us to reconsider what paediatric trainees need to know and do in preparation for their consultant careers. With two or, at most, three years in which to master a speciality, the aims of training and the job content must be clearly defined. This is particularly true of community paediatrics, because it incorporates many different areas of practice, and clinical learning opportunities are not concentrated on one site as they are in hospital medicine or on one list as in primary care.

No two community paediatricians have exactly the same job description. ${ }^{1}$ Virtually all assume an element of clinical service to individual children, but most also include some "public health" activities designed to improve the care of specified groups of children or to measure and change the health status of the whole child population. Lennart Kohler defines the tasks of child public health as "placing the health of children and their families in their full social, economic, and political context" and believes this is "the responsibility of decision makers in all organisations in all sectors of the economy". 2

A series of articles to be published in the Archives over the coming months will review many aspects of child public health. The authors have been asked to consider what can be achieved by adopting a public health perspective, how improvements in health can be gained and measured, what role paediatricians might have in this process, and how they should be trained. This topic is timely in view of the government's support for public health and health promotion.

\section{Delivery of medical care for individual children}

Clinical services deal with a range of children's health problems in a variety of settings. The term "ambulatory paediatrics" refers to delivery of care not needing admission to hospital. Most community paediatrics is ambulatory, but hospital inpatient care now plays only a small role in most specialities and even complex disorders can be managed largely at home. Community paediatricians historically have been particularly associated with assessment and care of children with disabilities, including both serious neurological disorders such as cerebral palsy and the more prevalent but less disabling problems such as behavioural and emotional problems, school difficulties, attention deficit hyperactivity disorder, and language impairments. Indeed, the complexity and volume of this work is thought by many to have reached the stage where it could be regarded as a speciality in its own right. Paediatric audiological services, originally part of the community paediatricians' portfolio, are now usually provided by staff working full time in audiology. Children suspected of having suffered abuse or neglect, looked after by the local authority, or being put forward for adoption often need special consideration, and statutory duties such as that of "designated doctor" must be fulfilled.

The planning and improvement of care for these special groups of children involves many other agencies. Paediatricians bring their clinical expertise to these discussions and meetings, generate new initiatives, and contribute to staff training. The same applies to early identification of disabil- ity through the primary care network and child health surveillance.

Applying public health insights to clinical practice

All paediatricians in training should have some exposure to public health concepts. ${ }^{3}$ They should learn to ask: is this child's illness the tip of an iceberg-for example, the child with haemolytic uraemic syndrome might be the first case in an outbreak of Escherichia coli O157. Does this case represent a new or emerging problem? If so, why? What data sources might help find out? Are there similar cases who are not referred, and if so, why? Was this case preventable? By what means? What community networks might be involved in the child's care and what do they need to know? In the case of new screening tests, what are the performance characteristics of the test? How can concepts such as sensitivity, specificity, and predictive values be applied to use of everyday tests in clinical work?

Paediatricians whose work is mainly general paediatrics will particularly want to know about the health needs of their area and how these are changing. They must know about the role of primary care and how small shifts in referral behaviours of general practitioners can translate into huge workload changes in secondary care. Clinicians working in disability or social paediatrics also need this knowledge, together with an understanding of the attitudes and perceptions of other professions. ${ }^{45}$

\section{The public health of children}

Improving the public health of children requires a different perspective from that of clinical practice. The aims are to measure and, where appropriate, try to improve the health status of populations or sub-populations of children, using a range of resources of which health care services for individual children is just one. Health also depends on socioeconomic circumstances, quality of the environment, housing, education, and nutrition. ${ }^{6}$ Change is achieved over a time scale of years and involves many factors, some of which are hard to measure or influence directly.

WHAT ARE THE TASKS?

The tasks regarded as "child public health" include:

- Introducing, changing, organising, and monitoring primary and secondary prevention measures such as immunisation, formal screening programmes, and child health promotion

- Assessing data, taking an objective view, and giving advice on health care provision issues for children ${ }^{7}$-for example, competing priorities, in terms of equity, public attitudes, and value for money

- Using personal skills and networks to negotiate and contribute to desired changes with other agencies-for example "Healthy Schools" initiatives 8 and injury prevention measures

- An advocacy role, using public health knowledge and data on-for example, inequalities, to influence and change attitudes and policies within government and 
society. The aim of advocacy is "to overcome structural (as opposed to individual or behavioural) barriers to public health goals". ${ }^{9}$

ARE THE TASKS WORTH DOING?

The short answer is "yes", of course. But it is often very difficult to measure the impact of public health initiatives, let alone dissect out the value of the contribution made by one individual or action. Clinicians receive instant feedback when they successfully treat a sick child, but the measure of success for public health actions is often that things stop happening - children do not develop infectious disease, do not suffer brain damage from untreated phenylketonuria, or are not injured in pedestrian accidents. Other low profile successes might be optimal use of staff and financial resources; introduction of new antibullying policies as part of health promotion in schools; provision of teenage clinics with a subsequent fall in teenage pregnancy rates; legislative changes such as safe packaging of drugs.

\section{WHAT ARE THE OBSTACLES?}

There are several. Many factors influence most of the activities described and the time scale is long, so academically sound research and evaluation are difficult to achieve and therefore to fund. ${ }^{10}$ Diverting resources from clinical medicine to preventive measures such as screening or health education is logical but difficult, in the face of escalating public demand for treatment and changing demography. Vested interests do not welcome many of the initiatives needed to bring about change. But perhaps the greatest obstacle is the shortage of enthusiastic management by committed individuals, without which it is all but impossible to change systems or guarantee quality preventive care services that work.

\section{Management issues in the public health of childhood}

Many health care professions and often other agencies are involved in public health initiatives. This cross fertilisation of ideas can be very creative, but it can also result in diffusion of responsibility and failure to allocate tasks to get the job done. Even an apparently simple task involving only health service staff, like auditing the delivery of the local BCG policy and eliminating weaknesses in the system, is time consuming and ultimately often depends on the determination of one individual. Moving from data collection and interpretation, to formulation and acceptance of a strategy, is no easy task, but implementation is even more challenging. The facility to get things done is an indispensable part of effective public health work.

\section{Who should take on the public health tasks of childhood?}

One thing is certain, there is so much to be done that there should be no sense of competition between public health professionals and community paediatricians. However, doctors are expensive and do not have a monopoly on public health expertise; the Minister for Public Health [Tessa Jowell] recently announced that other professions including nurses, pharmacists, and environmental health officers would be eligible to become consultants in public health.

In the past, the public health overview was the responsibility of the Medical Officer of Health, and after the 1974 reorganisation this passed to the Specialist in Community Medicine (Child Health) (SCM $(\mathrm{CH})$ ) who had an overview of child health in the district, including acute services, community, regional networks, etc. These posts have now disappeared; some of the duties of the SCM have been assumed by the new generation of community paediatricians, some by clinical directors, and others by public health medicine specialists, but the paediatric perspective and knowledge of an individual with no particular clinical axe to grind is not currently available in every district.

The SCM $(\mathrm{CH})$ role was a full time job; is it full time now in 2000? Is it possible to develop and maintain clinical skills at the level expected for a consultant community paediatrician while also performing as an effective public health consultant? And can a consultant in generic public health medicine, with a wide range of responsibilities, find the time to acquire and nurture a special interest in children's issues? Neither is impossible, but as training has become shorter and demands are growing, both will become increasingly difficult. Either clinical care or public health will suffer. Community paediatricians might maintain existing systems and procedures, and take on specific roles (for example, immunisation coordinator) but those who want to make a real difference to population health need to take on the public health tasks as their main job-it is too big and too demanding to be done in the odd afternoon.

Is there a role in child public health for today's trainees? A specialist registrar in public health medicine could undertake two or three years of paediatric training to become familiar at first hand with clinical issues and problems. Alternatively, a paediatric specialist registrar who had a major interest in this area could study public health medicine as part of community child health training, perhaps using their optional year 5 to do an MSc and seeking an additional year's training or a fellowship. The advantage of developing an interest in the public health of children early in one's career is the opportunity to make a major contribution, develop research programmes, and perhaps establish academic departments of paediatric public health.

There are some practical problems. After two years' clinical work the public health trainee would still have less insight into clinical issues than someone with a full paediatric training. Some public health consultants have forged working partnerships with clinicians and this need not be a significant deficiency. On the other hand, the paediatric specialist registrar might have difficulty in obtaining a clinical consultant post because their clinical experience would be significantly less than that of a full time clinician, yet their public health training would not be sufficient for them to enter a public health post.

Another option is for a consultant paediatrician to make a formal career move into public health. Many non-surgical clinicians show a career progression from acute work through less acute to chronic and cold cases, and then become interested in improving the system as opposed to individual patient care. The benefits of this route are that they have long experience behind them so they can maintain clinical skills if they so wish, they probably have increased credibility with colleagues, they know the practicalities of what can be done, and they have probably had some management experience already. They would undertake this role within an existing consultant post, so it would be a low risk strategy as compared to the first option. A personal development plan involving a formal MSc programme, followed by a period of mentoring by a public health specialist, might be a requirement. Such people would probably be less likely to develop a long term academic or research programme on their own, but might form very effective and productive partnerships with career public health colleagues, and could perhaps make a useful contribution in international child health. 


\section{The debate}

In this article I have tried to define the public health role for children, asked who should fulfil these roles, and noted that doctors are not the only possible candidates. I have argued that although clinicians and public health specialists can and must learn from each other, doing both jobs well is becoming increasingly challenging. Questions have been raised about the changing nature of the job undertaken by community paediatricians, the extent to which public health medicine is also a management task, and the magnitude of the benefits arising from public health work.

As children become physically healthier and the old diseases decline in significance, paediatrics must change. Many of the current health concerns of children are related to environmental and social pressures and cannot be addressed only as individual clinical problems. There should be substantial benefits from a greater commitment to public health work for children. We need to review the evidence about what works and why, and assess the level of investment that should be made in this work.

Finally, returning to the concerns that prompted this article, paediatricians and public health specialists must consider the public health training needs of all paediatricians and other professionals wishing to specialise in this field.

- Should some or all of this work come under the umbrella of community paediatrics?

- How many trainees should be encouraged to enter this field?
- What might primary care groups and trusts want them to do?

Future articles in this series will address these and related questions.

So many colleagues have contributed to the ideas set out here that I cannot thank them all, but many of them will be authors of further articles in this series and if they do not agree with my conclusions they will make this abundantly clear.

University of Sheffield and Community Health Sheffield,

Institute of General Practice, Northern General Hospital,

Sheffield S5 7AU, UK

email:d.hall@sheffield.ac.uk

1 Boon A, Lynch M, Macfarlane JA, Waterston A. Essential of effective community health services for children and young people. London: Royal College of Paediatrics and Child Health, 1997.

2 Kohler L. Child public health: a new basis for child health workers. European fournal of Public Health 1998;8:253-5.

3 Rushdy A, O'Mahony M. PHLS overview of communicable diseases 1997: results of a priority setting exercise. Commun Dis Rep CDR Suppl 1998;8(5):S1-12.

4 Coleridge P. Disability, liberation and development. Oxford: Oxfam, 1993.

5 Walker A, Walker C. Britain divided: the growth of social exclusion in the 1980s and 1990s. London: Child Poverty Action Group, 1997.

6 Taggart SCO. The healthy city. $\mathcal{F} R$ Coll Physicians Lond 1998;32:568-71.

7 Conroy S, Smith M. Exploring infant health. London: Foundation for the Study of Infant Deaths, 1999.

8 Jamison J, Ashby P, Hamilton K, Lewis G, MacDonald A, Saunders L. The health promoting school: final report of the ENHPS evaluation project in england. London: Health Education Authority, 1998.

9 Chapman S, Lupton D. The fight for the public health. London: BMJ Publishing Group, 1994:6.

10 Expert Working Group. Moore HL, chair. Promoting the health of children and young people: setting a research agenda. London: Health Education Authority, 1999 